\title{
An autosomal recessive syndrome of cleft palate, cardiac defect, genital anomalies, and ectrodactyly (CCGE)
}

\author{
Aldo Giannotti, Maria Cristina Digilio, Rita Mingarelli, Bruno Dallapiccola
}

\begin{abstract}
We report a brother and sister affected by a constellation of malformations, including cleft palate, cardiac defect, genital anomalies, and ectrodactyly (CCGE). A similar association has been reported previously by Richieri-Costa and Orquizas in a male patient born to consanguineous parents. An autosomal recessive pattern of inheritance is proposed for this syndrome.
\end{abstract}

(f Med Genet 1995;32:72-74)

Richieri-Costa and Orquizas ${ }^{1}$ reported a Brazilian boy born to healthy, consanguineous parents affected by a constellation of malformations, including ectrodactyly, cleft lip/palate, congenital heart defect, genital anomalies, and mental retardation. Since none of the known syndromes involving clefting-ectrodactyly or clefting-genital anomalies had ever documented the full spectrum of anomalies found in their patient, this constellation of malformations was reported as a "new multiple congenital anomaly/mental retardation syndrome". We describe here a brother and sister presenting with a syndrome strikingly similar to that observed by Richieri-Costa and Orquizas, ${ }^{1}$ and suggest autosomal recessive inheritance of this syndrome.

Department of Medical Genetics, Bambino Gesù Hospital, IRCCS, Salita S Onofrio 4, 00165 Rome, Italy A Giannotti M C Digilio

Department of Public Health and Cell Biology, University of Tor Vergata, Rome and Department of and Department of Medical Genet San Giovanni Rotondo, Italy R Mingarelli B Dallapiccola

Correspondence to: Dr Giannotti.

Received 18 May 1994 Revised version accepted for publication

1 September 1994

Case 1, a male, was the second child of healthy, non-consanguineous parents. The mother was 30 years old at delivery and the father was 32. Pregnancy was complicated by threatened abortion at 4 months. In the 33rd week of gestation fetal ultrasound showed delayed fetal growth, oligohydramnios, and a complex congenital heart defect. The baby was delivered at term by caesarean section. Birth weight was $1550 \mathrm{~g}$, length $40 \mathrm{~cm}$, and head circumference $31 \mathrm{~cm}$ (all below the 3 rd centile). Apgar scores were 2 at one minute, 4 at five minutes, and 9 at 10 minutes.

On clinical evaluation shortly after birth a dolichocephalic skull, high forehead, flat nasal bridge, blepharophimosis, bulbous tip of the nose with hypoplastic nares, flat philtrum, small mouth with thin lips, high arched palate, micrognathia, and large, low set, and dysmorphic ears were recorded (figure A, B). The neck was short. Pectus excavatum and increased internipple distance were also noticed. Heart auscultation indicated a $3 / 6$ systolic murmur. The patient had hypospadias and micropenis, a hypoplastic scrotum, and no testes were palpable (figure $\mathrm{C}$ ). The hands showed bilateral ectrodactyly with absence of the third finger and a cleft between the second and fourth fingers (figure D). The feet were normal.

Routine blood chemistry disclosed no abnormality. Chromosomal analysis showed a normal male karyotype.

$X$ ray examination showed upper limb anomalies, including bilateral cleft hand with agenesis of the third finger. Cerebral and renal ultrasound were unremarkable. On echocardiography a complex congenital heart defect was detected, consisting of atrial septal defect ostium secundum type, mitral atresia and hypoplastic left ventricle, a large posterior ventricular septal defect, preductal aortic coarctation, and persistent ductus arteriosus.

The patient died at 1 month of age from circulatory insufficiency.

Necropsy confirmed the cardiac malformation. No gross cerebral or renal anomaly was found. There was a mesenterium communis. The testes were in the inguinal canals, but a rudimentary atretic vagina located in the scrotal median raphe was also present.

An older sister of the patient (case 2) had died at 6 hours of life in association with prematurity. Based on clinical records, she was born by vaginal delivery in the seventh month of gestation. The pregnancy was complicated by oligohydramnios and retarded fetal growth. Birth weight was $1050 \mathrm{~g}$. She had facial dysmorphism, cleft palate, bilateral ectrodactyly of the hands, and cutaneous syndactyly of toes 2 to 5. No additional gross congenital anomalies were found at necropsy.

The family history was otherwise unremarkable.

\section{Discussion}

These two sibs showed a constellation of defects strikingly similar to that reported in a single patient by Richieri-Costa and Orquizas. ${ }^{1}$ The cardinal features of this malformation complex include ectrodactyly, cleft lip/palate, congenital heart disease, micropenis, and mental retardation. Distinction from other syndromes presenting with clefting-ectrodactyly appears clear. The absence of ectodermal involvement and the presence of congenital heart defect differentiate this disorder from the EEC (ectrodactyly, ectodermal dysplasia, clefting) syn- 

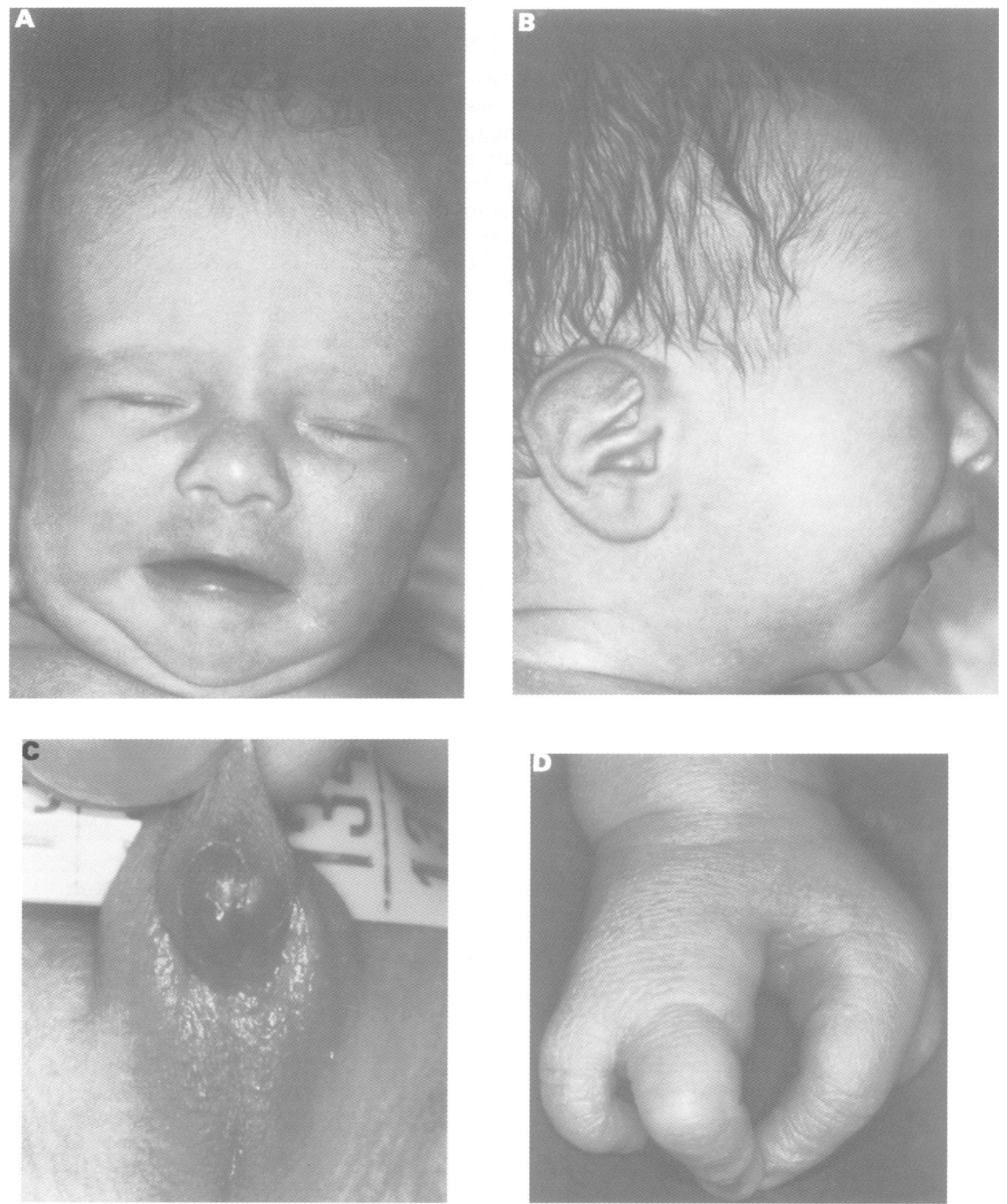

Frontal (A) and lateral (B) facial appearance, genitalia (C) and hand (D) of case 1.

drome. $^{2}$ The existence of an autosomal dominant ectrodactyly-clefting syndrome without ectodermal or tear duct anomaly has been suggested. ${ }^{3}$ The reported cases with this condition had, however, no additional mal-

Clinical findings of patients with CCGE syndrome

\begin{tabular}{|c|c|c|c|}
\hline \multirow[t]{2}{*}{ Findings } & \multirow{2}{*}{$\begin{array}{l}\text { Richieri-Costa } \\
\text { and Orquizas }\end{array}$} & \multicolumn{2}{|c|}{ Present report } \\
\hline & & Case 1 & Case 2 \\
\hline Sex & $M$ & $\mathbf{M}$ & F \\
\hline Low birth weight & - & + & + \\
\hline Cleft lip/palate & + & - & + \\
\hline Congenital heart defect & $\stackrel{+}{\text { VSD }}$ & $\begin{array}{l}++ \\
\text { ASD, MA, } \\
\text { VSD, AC }\end{array}$ & \\
\hline Micropenis & + & + & \\
\hline $\begin{array}{l}\text { Cryptorchidism } \\
\text { Cleft hand }\end{array}$ & $\begin{array}{l}+ \\
+\end{array}$ & $\begin{array}{l}+ \\
+\end{array}$ & + \\
\hline Cleft foot & + & - & - \\
\hline Syndactyly of toes & & -7 & + \\
\hline Mental retardation & + & NR & NR \\
\hline
\end{tabular}

VSD $=$ ventricular septal defect, $\mathrm{ASD}=$ atrial septal defect, $\mathrm{MA}=$ mitral atresia, $\mathrm{AC}=$ aortic coarctation, $\mathrm{NR}=$ not relevant. formations. Among the known clefting conditions associated with genital anomalies, the Malpuech syndrome ${ }^{4}$ can be excluded on the basis of the absence of limb defects. Congenital heart defect, cleft palate, and genital anomalies have been found in the genitopalatocardiac syndrome. ${ }^{5}$ However, none of the known affected cases had ectrodactyly. Cardiac defect, cleft lip, ectrodactyly and genital anomalies are described in the oculocerebroacral syndrome. ${ }^{6}$ However, this latter malformation complex also includes cerebral and ophthalmological anomalies, which are not present in our patients.

The clinical findings in our patients and in the case described by Richieri-Costa and Orquizas $^{1}$ are summarised in the table. The striking phenotypic overlap between these three patients suggests that they are affected by the same clinical condition, although ectrodactyly was the only feature found in all three cases 
and a variable intrafamilial expression of the malformation pattern was apparent in our patients. In fact, these two sibs were not concordant for congenital heart defect and cleft palate. Parental consanguinity in the first reported case and the recurrence of this condition in two sibs born to unaffected parents in the present report support autosomal recessive inheritance of this syndrome. Thus, a one in four recurrence risk appears suitable for the parents of these patients. Finally, prenatal ultrasound examination of pregnancies seems appropriate for fetal detection of this syndrome in parents with an affected child.
1 Richieri-Costa A, Orquizas LC. Ectrodactyly, cleft lip/palate, ventricular septal defect, micropenis and mental retardation in a Brazilian child born to consanguineous parents. Rev Bras Genet 1987;X:787-92.

2 Rodini ESO, Richieri-Costa A. EEC syndrome: report on 20 new patients, clinical and genetic considerations. $A m \mathcal{F}$ (1990;37:42-53.

3 Rodini ESO, Freitas JAS, Richieri-Costa A. Ectrodactyly, cleft lip/palate syndrome. Am F Med Genet 1991;38:539-41.

4 Malpuech G, Demeocq F, Palcoux JB, Valiefering P. A previously undescribed autosomal recessive multiple conviously undescribed autosomal recessive multiple con-
genital anomalies/mental retardation (MCA/MR) genital anomalies/mental retardation (MCA/MR)
syndrome with growth failure, lip/palate cleft(s), and uro-

5 Greena F, Gresi MV, Carpenter RI, Law SW, Hoffman LP, Ledbetter DH. The Gardner-Silengo-Wachtel or genito-palato-cardiac syndrome: male pseudohermaphroditism with micrognathia, cleft palate, and conotruncal cardiac defect. Am f Med Genet 1987;26: $59-64$.

6 Atkin JF, Patil S. Apparently new oculo-cerebro-acral syndrome. Am F Med Genet 1984;19:585-7. 